\title{
ENEM EM LIBRAS COMO CORPUS LINGUIISTICO: METODOLOGIA PARA PRODUÇÃO DE GLOSSÁRIOS EM LIBRAS
}

\author{
ENEM IN LIBRAS AS LINGUISTIC CORPUS: \\ A METHODOLOGY FOR THE PRODUCTION OF GLOSSARIES \\ IN LIBRAS
}

\author{
Gláucia Caroline Silva-Oliveira \\ Universidade Federal do Pará, Bragança, Pará, Brasil \\ gcoliveira@ufpa.br
}

\begin{abstract}
Débora Campos Wanderley Universidade Federal de Santa Catarina, Florianópolis, Santa Catarina, Brasil deboraufsclibras@gmail.com

Marianne Stumpf

Universidade Federal de Santa Catarina, Florianópolis, Santa Catarina, Brasil stumpfmarianne@gmail.com
\end{abstract}

Resum0: A implementação das políticas linguísticas e de acessibilidade tem contribuído para a ampliação dos espaços de atuação da comunidade surda. Exemplo disso é o Exame Nacional do Ensino Médio (Enem), que desde 2017 tornou-se acessível para estudantes surdos apresentando a prova traduzida para a Língua Brasileira de Sinais (Libras). Dessa forma, a videoprova pode ser considerada como um documento de registro da língua em questão para as diversas áreas do conhecimento a qual o exame se destina. Assim, este artigo propõe a prova do Enem em Libras como corpora linguísticos para estudos léxico-terminográficos, bem como delimita os passos metodológicos para a construção de um Glossário em Libras digital, tendo como exemplo a área de ciências biológicas. O presente trabalho fundamenta-se na teoria comunicativa da terminologia proposta por Cabré (1999) focada nos princípios da poliedricidade do termo, do caráter comunicativo da terminologia e na variação. Esta proposta é importante por viabilizar que o pesquisador compile seu próprio banco de dados e material de pesquisa, além disso, contribui para o aprimoramento do fazer terminográfico e para a ampliação dos registros de terminologias nas diversas áreas do conhecimento.

Palavras chave: Terminologia; Corpora; Linguística; Libras; Enem

Abstract: The implementation of language and accessibility policies has contributed to the expansion of spaces for the deaf community. The National High School Exam (Exame Nacional do Ensino Médio - Enem) is an example. It has become accessible to deaf students since 2017 by presenting its translated content to Brazilian Sign Language (Libras). Thus, the videoprove can be considered as a register of this language for the various areas of knowledge. This work aims to contribute to the improvement of terminographic making and broaden the terminology records in the various areas of knowledge by presenting the potential of the Enem test in Libras a linguistic corpora for lexicoterminographic studies and proposing the methodological steps 
for the construction of a Glossary in Libras. example of biological sciences. The work is based on corpus theory of linguistics and on the communicative theory of terminology proposed by Cabré (1999) focused on the principles of the term polyhedricity, the communicative character of terminology and variation. This proposal is interesting, as it contributes to the improvement of terminographic making and to the expansion of terminology records in the various areas of knowledge, enabling the researcher to compile his own database and research material. Keywords: Terminology; Corpora; Linguistics; Libras; Enem

\section{INTRODUÇÃO}

As lutas históricas por um ensino de qualidade têm estrita relação com o acesso à língua de sinais. A partir de 2002, quando se reconheceu o status linguístico da Libras por meio da Lei 10.436 (BRASIL, 2002), a educação de surdos passou a ser mais discutida, reconhecendo-se o caráter bilíngue e a complexidade do acesso a língua nos diversos contextos sociais. O Decreto $\mathrm{n}^{\mathrm{o}}$ 5.626, de 22 de dezembro de 2005 (BRASIL, 2005) trouxe a regulamentação desta Lei ressaltando a presença obrigatória da Libras em espaços formativos de profissionais da educação e da saúde; a necessidade da qualificação de profissionais bilíngues como tradutores e intérpretes de Libras (TILS), professores bilíngues, professores e instrutores de Libras; garantia de amplo atendimento, por meio do uso e da difusão da Libras e da tradução e da interpretação de Libras - Língua Portuguesa. Além disso, dispôs que as instituições federais de ensino, deveriam garantir às pessoas surdas condições de acesso em seus processos seletivos (BRASIL, 2005). Diante disso, a luta por uma educação bilíngue se intensifica, sendo também assegurada pelas Metas e Estratégias do Plano Nacional de Educação:

\footnotetext{
Meta 1. Estratégia 1.11- Priorizar o acesso à educação infantil e fomentar a oferta do atendimento educacional especializado complementar e suplementar aos (às) alunos (as) com deficiência, transtornos globais do desenvolvimento e altas habilidades ou superdotação, assegurando a educação bilíngue para crianças surdas e a transversalidade da educação especial nessa etapa da educação básica;

Meta 4. Estratégia 4.7- Garantir a oferta de educação bilíngue, em Língua Brasileira de Sinais - LIBRAS como primeira língua e na modalidade escrita da Língua Portuguesa como segunda língua, aos (às) alunos (as) surdos e com deficiência auditiva de 0 (zero) a 17 (dezessete) anos, em escolas e classes bilíngues e em escolas inclusivas ..., bem como a adoção do Sistema Braille de leitura para cegos e surdoscegos (PNE, 2014-2024).
}

O acesso ao ensino superior apresentou diversas adaptações para se alinhar a legislação vigente, de forma que, após cinco anos da publicação do Decreto 5.626 ocorreu o primeiro vestibular presencial com prova vídeo-gravada em Libras com pioneirismo da Universidade Federal de Santa Maria, Rio Grande do Sul. Entretanto, as provas não apresentam divulgação eletrônica limitando inúmeras possibilidades de consulta, estudos e pesquisas (ROCHA; LACERDA, 2016).

Outras instituições promoveram a acessibilidade da prova em Libras, mas restringiram-se a uma única versão desta. Apenas a Universidade Federal de Santa CatarinaUFSC oferece vestibular em Libras de forma ininterrupta desde 2006, tendo a expertise de vestibular em Libras em ensino à distância com as provas divulgadas eletronicamente (QUADROS; SOUZA; VARGAS, 2012). Em contrapartida, o Enem apresentou sua primeira versão de prova vídeo-gravada em Libras em 2017 e vem gradativamente aprimorando aspectos da acessibilidade e usabilidade dos vídeos em uma plataforma online no site do Instituto Nacional de Estudos e Pesquisas Educacionais Anísio Teixeira (http://www.inep.gov.br/). 
A prova vídeo-gravada em Libras constitui-se em um registro desta língua com produção nas diversas áreas do conhecimento, configura-se como poderosa fonte de estudo, apropriação e pesquisa em língua de sinais. Segundo Quadros (2016) corpus linguístico pode ser definido como "um banco de produções de uma língua, organizado por diferentes tipos de textos (orais, sinalizados e/ou escritos), para fins de registro da língua". Para Sardinha (2004) é um conjunto de dados linguísticos coletados criteriosamente, sendo alvo da linguística de corpus. Dessa forma, a grande coletânea de vídeos em Libras compõe corpora linguístico autêntico, permitindo evidenciar e quantificar padrões por meio de ferramentas e de estatísticas computacionais. Além de favorecer o armazenamento, registro, organização, processamento dos dados e análise do corpus.

Dessa forma, o presente artigo propõe a prova em Libras do Enem como corpora linguístico, pois reune uma coletânea de vídeos e delimita os passos metodológicos para a construção de uma obra terminográfica em uma língua visuo-espacial. Para tanto, este trabalho compõem-se das seguintes sessões: a primeira aborda as questões de acessibilidade e estrutura da prova do Enem; a segunda discorre sobre as implicações da teoria de Cabré (1999) sobre o potencial do Enem em Libras como corpora linguístico e a terceira sobre os caminhos metodológicos para a construção de um glossário em Libras tendo como modelo a produção de um glossário de ciências biológicas.

\section{O ENEM: PROVA EM LIBRAS}

O Enem é um instrumento avaliativo planejado e aplicado pelo Instituto Nacional de Estudos e Pesquisas Educacionais Anísio Teixeira (INEP), é uma autarquia vinculada ao Ministério da Educação (MEC). Desde 1998, afere as competências e habilidades adquiridas ao longo da educação básica de concluintes e egressos do ensino médio que contribuem para o desenvolvimento de estudos e indicadores educacionais (INEP, 2019).

O Enem é um exame anual, de abrangência nacional com metodologia de análise baseada na Teoria de Resposta ao Item (TRI), que considera o grau de dificuldade das questões; o poder de discriminação entre os itens que denotam a proficiência requisitada e mecanismos que minimizam os acertos ao acaso (chute). Tal aspecto da prova contribuiu para que o MEC a instaurasse como a principal via de acesso às universidades federais a partir de 2009 (MEC, 2019). Além de colaborar para o acesso ao ensino superior no Brasil por meio do Sistema de Seleção Unificada (Sisu) e do Programa Universidade Para Todos (Prouni), oportuniza a participação de estudantes brasileiros em convênios com pelo menos 35 instituições internacionais, especificamente em Portugal (MEC, 2019).

Da primeira edição em 1998 a 2017 o número de inscritos para o exame passou de 157.221 para 6.763.122 e o número de municípios com aplicação da prova de 184 para 1.725 demonstrando a grande adesão nacional ao Enem. Ao longo destes 20 anos de aplicação do exame muitas foram as adaptações e melhorias realizadas. Dentre elas, destaca-se a política de acessibilidade e inclusão que garantiu recursos como prova em braile, prova com letra ampliada e superampliada, ledor, guia-intérprete, transcritor, tradutor-intérprete de Libras, videoprova em Libras, tempo adicional e sala de fácil acesso e/ou com mobiliário acessível.

A videoprova em Libras passou a ser adotada a partir de 2017 em resposta a uma reivindicação da comunidade surda brasileira. Nesta mesma edição do Exame o tema da redação direcionou a atenção para a comunidade surda com o tema "Desafios para a formação educacional de surdos no Brasil" ampliando o espaço para discussão e maior visibilidade sobre esta questão no cenário nacional.

A videoprova apresenta a tradução dos enunciados e alternativas das 180 questões em Libras (Figura 1) permitindo que os participantes surdos acessem o conteúdo diretamente em 
sua língua natural nas diversas provas que compõem o exame, a saber: (1) Provas de Linguagens, Códigos e suas Tecnologias; (2) Prova de Ciências Humanas e suas Tecnologias; (3) Prova de Ciências da Natureza e suas Tecnologias; e (4) Prova de Matemática e suas Tecnologias. Além disso, os participantes surdos também são avaliados por meio de uma redação, que exige o desenvolvimento de um texto dissertativo-argumentativo em língua portuguesa, como segunda língua.

Figura 1 - Videoprova em Libras do Enem 2018 de Ciências da Natureza e suas Tecnologias.

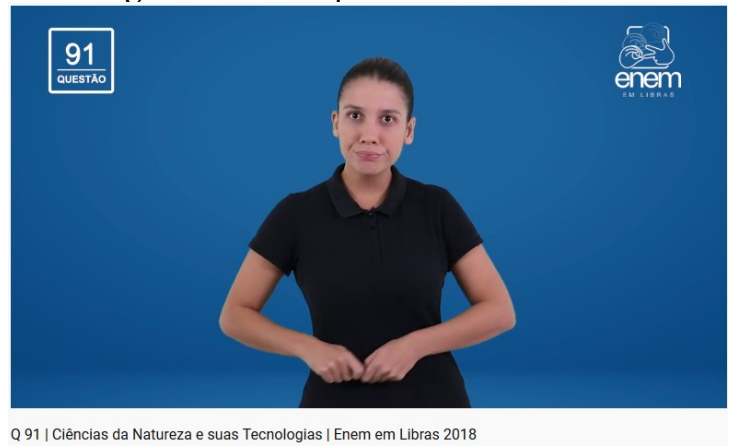

(a)

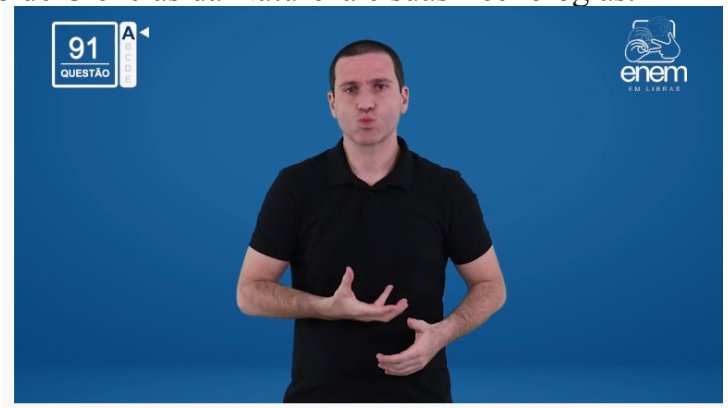

Q 91 | Ciências da Natureza e suas Tecnologias | Enem em Libras 2018

(b)

Legenda

(a) Enunciado da questão 91 .

(b) As alternativas das questões.

Fonte: INEP (Disponível em: http://portal.inep.gov.br/educacao-basica/enem/enem-em-libras)

\section{AS CONTRIBUIÇÕES DO ENEM EM LIBRAS PARA OS ESTUDOS TERMINOLÓGICOS}

A implantação de políticas linguísticas, de inclusão e de acessibilidade ocorridas nas últimas décadas possibilitou maior participação social dos surdos. De forma que a Libras nunca esteve tão visível e divulgada na sociedade brasileira, principalmente nos últimos cinco anos. Diante de um novo quadro social os surdos participam de diversos contextos e situações interacionais, que aumentam as demandas comunicativas requerendo maior versatilidade do léxico para suportar o cabedal vocabular, em um território novo, repleto de descobertas e novas denominações.

A chegada dos surdos à universidade é um exemplo deste aumento na demanda comunicativa que segundo Santos (2017) tem impulsionado a expansão lexical da Libras em ambiente acadêmico. No caso do ensino superior e técnico a linguagem de especialidade nas diversas áreas do conhecimento tem sido foco de vários estudos que têm permitido a coleta, o registro e a elaboração de obras léxico-terminográfica em Libras (COSTA, 2012; LIMA, 2014; DOUETTES, 2015; NASCIMENTO, 2016; CARDOSO, 2017). Tais produções estão ancoradas em pressupostos teóricos-metodológicos da Teoria Comunicativa da Terminologia, que consideram os recursos metafóricos e metonímicos, a sinonímia, a polissemia como uma realidade natural da linguagem técnica-científica (CABRÉ, 1999).

A Teoria Comunicativa da Terminologia (TCT) é a que mais se adequa a descrição e análise das unidades léxicas de valor especializado. Para Cabré (1999) a Terminologia está assentada em um tripé indissociável que integra fundamentos procedentes das ciências da linguagem, das ciências da cognição e das ciências sociais. Assim, apresenta a unidade terminológica sob o aspecto da poliedricidade, sendo simultaneamente uma unidade linguística, uma unidade cognitiva e uma unidade sociocultural. Determina ainda que, a prática terminológica é também tridimensional e que esta permite a liberdade de análise a partir de 
diferentes ângulos de forma independente. Além disso, a TCT considera a importância social da Terminologia para a resolução de problemas e questões informacionais e comunicativas em uma sociedade em que o conhecimento especializado e o plurilinguismo ganham cada vez mais espaço. Enfatiza o aspecto versátil permitindo adequações do fazer terminográfico em diferentes sociedades, contextos, finalidades, recursos e a matéria que queira abranger (CABRÉ, 1999).

A prova do Enem em Libras é um marco para a comunidade surda brasileira, sendo um documento de registro representativo da Libras em contexto científico nas diversas áreas do conhecimento. Dessa forma, salientamos o seu potencial como corpus linguístico, sendo base de dados para diversos estudos e, principalmente, estudos de cunho Terminológico, pois apresenta:

a) Acesso livre eletronicamente o que permite consulta ilimitada e amplo alcance e disseminação;

b) O registro em vídeo disponível para download. Por se tratar de uma língua visoespacial, o registro do movimento é de fundamental importância para que a comunicação seja eficiente;

c) Tradução de conteúdo específico de quatro grandes áreas do conhecimento: Linguagens, Ciências Humanas, Ciências da Natureza e Matemática. O que permite uma alta amostragem de sinais de especialidade;

d) Tradução realizada por TILS fluentes em Libras em sua maioria surdos, o que proporciona maior naturalidade e clareza nas traduções respeitando as características linguísticas de uma língua viso-espacial;

e) É um material de produção anual o que permite a inclusão de novos termos periodicamente e o registro de variações a cada nova edição do exame;

f) Divulgação de diversas terminologias, suprindo uma necessidade vocabular que tem motivado no Brasil o surgimento de neologismos dispersos e pouco usuais, uma vez que, é fruto de esforço individual ou de grupos isolados o que limita a disseminação e a sistematização dos termos.

g) A possibilidade de acompanhar ao longo do tempo os processos de formação e emprego dos termos nos diferentes contextos, pois o Enem é uma prova que relaciona o conhecimento científico às inovações tecnológicas da sociedade, sendo um instrumento valioso para estudos em longo prazo.

\section{CAMINHOS METODOLÓGICOS PARA A CONSTRUÇÃO DE UM GLOSSÁRIO EM LIBRAS}

Os passos que conduzem à produção de uma obra terminográfica em Libras com registro digital perpassam por caminhos que se conectam a diferentes áreas e comprova a natureza interdisciplinar do fazer terminológico. Integra as áreas de especialidade, lexicologia, da tradução, do design, das tecnologias digitais, dentre outras. Propomos aqui as etapas que conduzem a produção de um glossário em Libras em plataforma digital, tendo como modelo o glossário de Biologia disponível na plataforma da UFSC.

O glossário de Biologia é uma obra totalmente digital elaborado por equipe multidisciplinar de profissionais e para a sua constituição podemos destacar cinco grandes etapas: (i) Definição do corpus linguístico; (ii) Coleta e registro de termos em ficha léxicoterminográfica; (iii) Definição de conceitos, exemplo e imagens na área de escopo do glossário; 
(iv) Tradução para a Libras como registro em vídeo; (v) Postagem e divulgação do material em plataforma digital (Figura 2).

Figura 2 - Panorama metodológico para a construção de um glossário em Libras

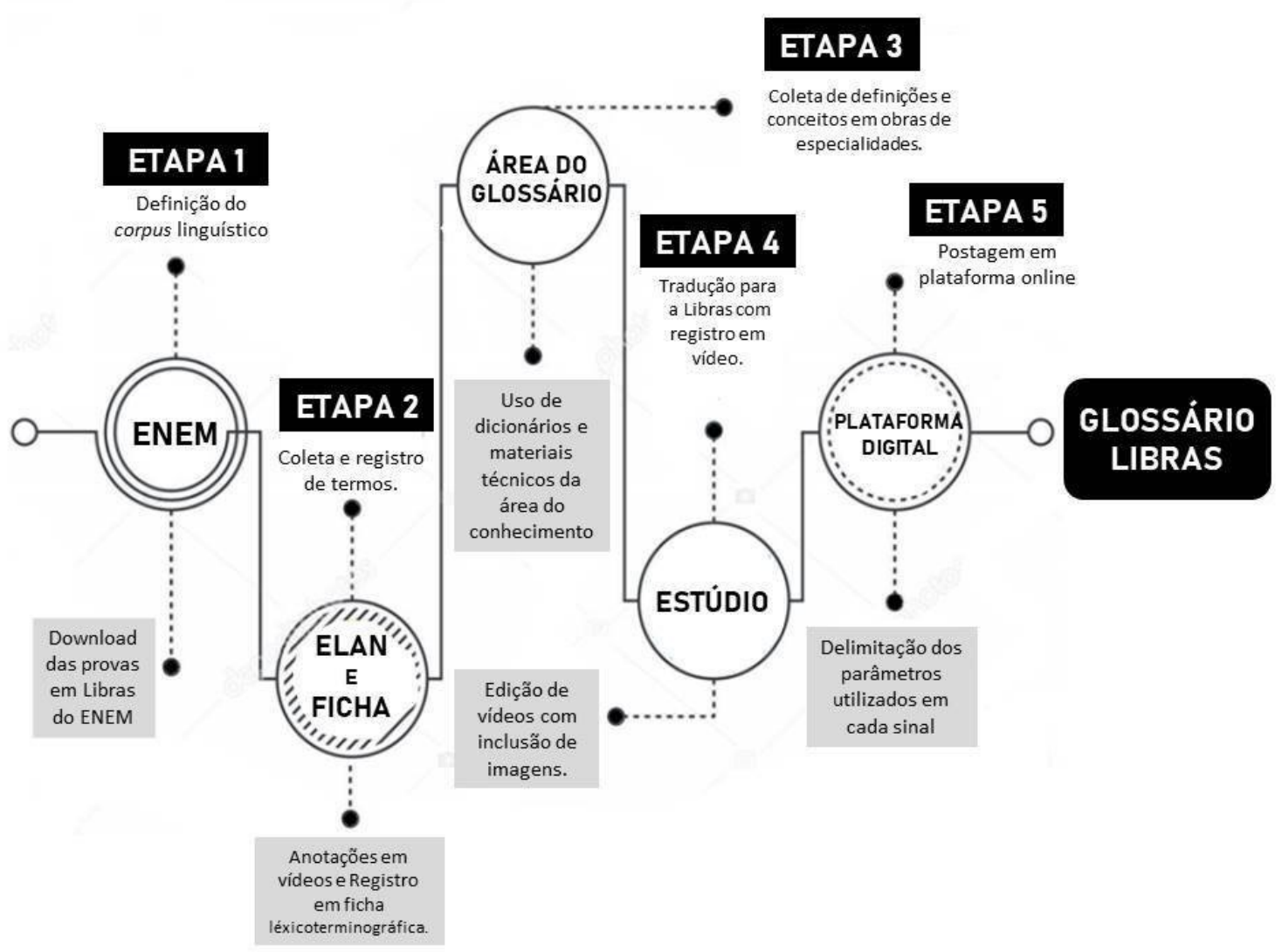

Fonte: elaborado pelas autoras.

\section{Etapa 01: Construção do corpus linguístico}

A prova do Enem é constituída por conteúdos do currículo do Ensino Médio, e os aborda contextualizando-os com as atualidades, inovações tecnológicas, política, cidadania, economia, saúde e etc. Essa forma de abordagem permite ricos contextos multi e interdisciplinares que se aproximam das práticas cotidianas, em que tudo se encontra interligado. Tal aspecto torna ainda mais rico o emprego de terminologias de diferentes áreas do conhecimento em uma única questão de prova, embora seja maior a demandada de esforço no processo de extração destes termos. Por isso, apoiamos fortemente as provas do Enem em Libras como corpora linguístico para a extração dos termos de especialidade com foco na construção de glossários em Libras.

No caso do glossário de Biologia a prova selecionada para a extração dos termos foi a de "Ciências da Natureza e suas Tecnologias", que avalia conhecimentos específicos de Biologia, Física e Química em um total de 45 questões por edição de prova.

O primeiro passo dessa construção foi baixar as versões de videoprova alvo do estudo, provas do Enem 2017 (http://enemvideolibras.inep.gov.br/2017/index.html) e 2018 (http://enemvideolibras.inep.gov.br/2018/index.html) para evitar problemas que venham a interferir na consulta como velocidade de carregamento, manutenção da página eletrônica dentre outros. Como a prova tem aspecto interdisciplinar foi necessário realizar a triagem das questões $(\mathrm{Q})$ que trabalham os conteúdos de ciências biológicas das demais áreas. Dessa forma, 
analisou-se um total de 90 questões, e suas respectivas alternativas, sendo 17 no Enem 2017 (Q93, Q96, Q99, Q101, Q102, Q103, Q105, Q108, Q114, Q117, Q120, Q123, Q126, Q129, Q132, Q133, Q135) e 18 questões no Enem 2018 (Q91, Q93, Q95, Q96, Q99, Q102, Q105, Q107, Q112, Q114, Q115, Q120, Q121, Q123, Q126, Q130, Q132, Q134) com conteúdos de biologia celular, bioquímica, botânica, ecologia, fisiologia, genética, saúde, zoologia dentre outras. Assim, 35 questões constituíram o corpus linguístico que serviu como base para a próxima etapa, a coleta e registro de termos das ciências biológicas.

\section{Etapa 02: Coleta e registro de termos em Libras}

O ELAN - Linguistic Annotator version 5.2, foi utilizado para subsidiar a extração dos termos, permitindo a transcrição em glosas dos termos identificados, em cada vídeo analisado. O registro dos termos envolveu o preenchimento de uma ficha léxico-terminográfica adaptada de Lima (2014) (Figura 3) que apresenta campos específicos direcionados ao termo em português e inglês; Fotos do sinal, links de vídeo referência e número da questão do Enem; Fotos do sinal variante, links de vídeo referência e a elaboração da escrita de sinais.

A escrita de sinais empregada foi o SignWriting-SW (http://www.signwriting.org/brazil/). Na internet há uma plataforma online usual permitindo a busca e o registro de novas grafias. Os sinais que não possuíam registros em $S W$ foram grafados com 0 auxílio do signpuddle (http://www.signbank.org/signpuddle2.0/index.php?ui=12\&sgn=46) de acordo com os critérios de escrita em Libras descritos por Barreto e Barreto (2015).

Figura 3 - Ficha léxico-terminográfica utilizada no presente estudo

\section{MODELO DE FICHA LÉXICO-TERMINOGRÁFICA}

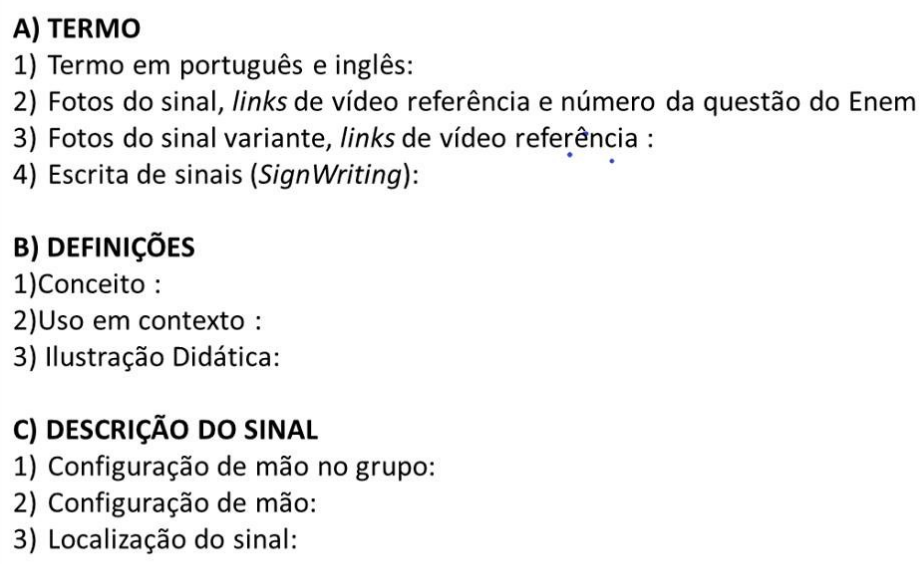

Fonte: adaptado de Lima (2014).

\section{Etapa 03: Coleta de definições e conceitos em obras de especialidades}

Para a composição dos conceitos e aplicações dos termos em contexto utilizou-se obras específicas da área a qual se propõem o glossário. No glossário de Biologia optou-se por coleções didáticas e dicionários da área (LESSA, 2007; AMABIS; MARTHO, 2004a; 2004b; 2004c; 2010) voltados para o nível de aprofundamento do conteúdo no ensino médio. Estas informações foram também registradas na ficha léxico-termográfica para cada termo extraído. 
As ilustrações didáticas foram elaboradas a partir de uma pedagogia visual de forma que complementasse as definições e contextos abordados para cada sinal registrado (BUZAR, 2009; LACERDA, 2011). Para a seleção das imagens utilizou-se a pesquisa a vários sites e edições foram realizadas para atender o aspecto visual, evidenciando elementos motivadores dos sinais termo, quando possível.

\section{Etapa 04: Tradução para a Libras como registro em vídeo}

As fichas elaboradas compõem o material de referência para as discussões, adaptações e traduções pela equipe de trabalho, principalmente pelos TILS. Os vídeos produzidos incluem o sinal de especialidade, sinal variante (se houver), a definição e o exemplo em Libras, totalizando até quatro vídeos em Libras. Todos os vídeos foram gravados com mesmo padrão de fundo e iluminação.

No glossário de biologia as ilustrações selecionadas foram incluídas ao vídeo, de forma que a imagem contribuísse para a aquisição de referência visual. Por ser uma plataforma eletrônica, as descrições dos parâmetros do sinal como configuração de mão (esquerda e direita); localização e movimentação foram registradas com auxílio de imagens representativas destas informações disponíveis na própria plataforma digital, bem como a seleção de um Binary SignWriting (BSW) para a inserção e registro da escrita de sinais.

\section{Etapa 05: Postagem e divulgação do material em plataforma digital}

Um total de 93 sinais-termo (Quadro 1) da especialidade biológica foi registrado no glossário de Libras. A ficha léxico-terminográfica apresenta-se adaptada aos campos disponíveis para o preenchimento na plataforma digital do Glossário de Libras da Universidade Federal de Santa Catarina (http://www.glossario.libras.ufsc.br/). Dessa maneira, para iniciar esta etapa recomenda-se que todos os campos das fichas estejam preenchidos e os arquivos para upload prontos (arquivo em formato $\mathrm{mp} 4$ : sinal, definição e exemplo em contexto).

Quadro 1 - Sinais da especialidade biológica registrados no glossário de Libras do presente estudo.

\section{(a)}

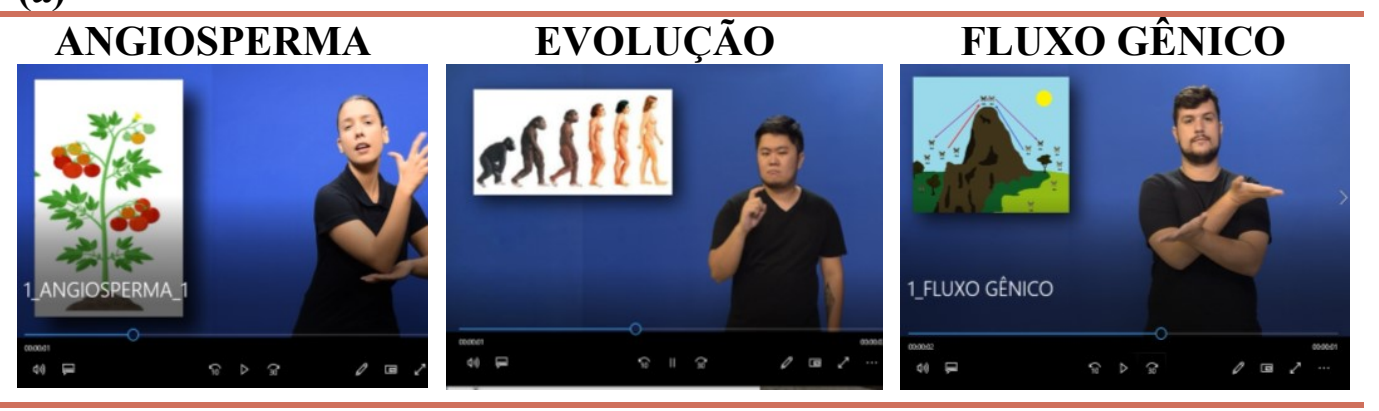

(b)

\begin{tabular}{ll}
\hline A & $\begin{array}{l}\text { AIDS. Alergia. Ambientalista. Anabolismo. Anfíbio. Angiosperma. Antibiótico. } \\
\text { Apoptose. Aquecimento Global. Arbusto. Artrópode. Atmosfera. Aves. }\end{array}$ \\
\hline B & Bactérias. Biodiversidade. Bioetanol. Bioma \\
\hline C & Cadeia Alimentar. Cálice (Floral). Carboidrato. Catabolismo. Célula. Chuva Ácida. \\
& $\begin{array}{l}\text { Ciclo Celular. Ciclo da Água. Coagulação do Sangue. Combustível Fóssil. Complexo } \\
\text { de Golgi. Componente Celular. Condensação. Corredor Ecológico. Cretáceo. }\end{array}$ \\
\hline D & DDT. Deserto. Digestão. DNA. Doença Parasitária. Doença Infecciosa. \\
\hline E & $\begin{array}{l}\text { Efeito Colateral. Epiderme. Especiação. Espécie. Estame. Estratificação Aquática. } \\
\text { Eutrofização. Evaporação. Evolução. }\end{array}$ \\
\hline
\end{tabular}




\begin{tabular}{ll}
\hline F & $\begin{array}{l}\text { Fagocitar. Fermentação. Flor. Floresta. Fluxo de Energia. Fluxo Gênico. Fundação } \\
\text { Owaldo Cruz. }\end{array}$ \\
\hline $\mathbf{G}$ & Gás Carbônico. Gás Oxigênio. Gene. Genótipo. Glicose. \\
\hline $\mathbf{H}$ & Hábitat. Herbicida. Hipoglicemia. Holometabolia. Hormônio. \\
\hline $\mathbf{I}$ & Invertebrado. \\
\hline $\mathbf{L}$ & Larva. Lipídio. Lixiviação. Lixo Orgânico. \\
\hline $\mathbf{M}$ & Manejo do Solo. Manguezal. Maré. Meio ambiente. Mitocôndria. \\
\hline $\mathbf{O}$ & Osso. \\
\hline $\mathbf{P}$ & Pétala. Pólen. Polinização. População. Pupa. \\
\hline $\mathbf{R}$ & Raiz Suporte. Répteis. Rio. RNA. Roedores. \\
\hline $\mathbf{S}$ & Síntese de DNA. Sintoma. Substância \\
\hline $\mathbf{T}$ & Transgenia. Tumor. \\
\hline $\mathbf{V}$ & Vacina. Variabilidade Genética. Vírus \\
\hline
\end{tabular}

Legenda:

(a) Imagem dos sinais-termo: angiosperma, evolução, fluxo gênico.

(b) Lista em português de todos os sinais-termo de ciências biológicas registrados no glossário em Libras-UFSC.

Fonte: elaborado pelas autoras.

\section{CONSIDERAÇÕES FINAIS}

Os caminhos metodológicos que levaram a elaboração desta obra podem ser amplamente aplicados às diversas áreas do conhecimento. Por ser um glossário digital há grande flexibilidade na inclusão de novos registros de termos, e de variantes, podendo ser considerado uma obra em constante construção. Além disso, as políticas de acessibilidades linguísticas fortalecem e asseguram o futuro da Prova em Libras do Enem, acreditamos fortemente, que esta veio para ficar. Consolidando uma conquista para a comunidade surda que além dos ganhos em acessibilidade, possibilita a difusão sem fronteiras desta língua de sinais. O glossário de Libras contribui para o trabalho de TILS, professores bilíngues que podem acessar os termos com rapidez e facilidade impulsionando o processo de consolidação e padronização dos sinaistermo. Dessa forma, um país com forte pressão monolíngue inaugura espaços onde outras línguas podem fluir com segurança e naturalidade como é o caso da Libras (BRASIL, 2002; 2005). Quadros e Karnopp (2004) sugerem que a língua de sinais deve estar presente em todos os momentos da vida do surdo permitindo que este amplie seu entendimento do mundo real.

A chegada dos surdos ao ensino superior e a presença da Libras como disciplina nos cursos de graduação contribuem também para este cenário. $O$ uso de obras léxicoterminográficas em Libras, que antes apresentavam-se direcionadas a um público mais específico, como TILS, professores bilíngues e estudantes surdos (STUMPF et al., 2014; 2015), hoje tem alcance ampliado atendendo a um público cada vez mais diverso que deseja se comunicar, entender e estudar as línguas de sinais. Este artigo, além de propor a prova do Enem em Libras como corpus linguístico para estudos léxico-terminográficos, descreve detalhadamente as etapas metodológicas para a construção de uma obra em língua de sinais, podendo ser extremamente útil e aplicável a outros estudos que se atenham ao registro de terminologias em diversas áreas do conhecimento contribuindo para a organização e celeridade neste processo. Esperamos que este estudo também possa contribuir com os profissionais pesquisadores de terminologia em Libras, estudiosos de terminologia e de corpus linguístico. E que também se ampliem os estudos e as discussões com os profissionais da área das ciências biológicas na busca progressiva para a construção, adaptação e consolidação dos sinais-termo nesta área do conhecimento. 


\section{REFERÊNCIAS}

AMABIS, José Mariano; MARTHO, Gilberto Rodrigues. Biologia: origem da vida, citologia e histologia, reprodução e desenvolvimento. São Paulo: Moderna, v.1, 2004a.

AMABIS, José Mariano; MARTHO, Gilberto Rodrigues. Biologia: biologia dos organismos. São Paulo: Moderna, v.2, 2004b.

AMABIS, José Mariano; MARTHO, Gilberto Rodrigues. Biologia: biologia das populações. São Paulo: Moderna, v.3, 2004c.

AMABIS, José Mariano; MARTHO, Gilberto Rodrigues. Biologia das células. São Paulo: Moderna, v.1, 2010.

BARRETO, M.; BARRETO, R. Escrita de Sinais sem mistérios. Belo Horizonte: Ed. do autor, v.2, 2015.

BRASIL, 2002. Lei $\mathbf{n}^{0}$ 10.436, de 24 de abril de 2002. Disponível em: http://www.planalto.gov.br/ccivil_03/leis/2002/110436.htm. Acesso em: 04 jan. 2020.

BRASIL, 2005. Decreto $\mathbf{n}^{0}$ 5.626, de 22 de dezembro de 2005. Disponível em: http://www.planalto.gov.br/ccivil_03/_Ato2004-2006/2005/Decreto/D5626.htm. Acesso em: 04 jan. 2020.

BUZAR, Edeilce Aparecida Santos. A singularidade visuo-espacial do sujeito surdo: implicações educacionais. 2009. 122 f. Dissertação (Mestrado em Educação) - Universidade de Brasília, Brasília, 2009.

CABRÉ, Maria Teresa. La terminologia: representación y comunicación. Elementos para una teoria de base comunicativa y outro articulos. Barcelona: Institut Universitari de Linguística Aplicada, Universitat Pompeu Fabra, 1999.

CARDOSO, Vilma Rodrigues. Terminografia da língua brasileira de sinais glossário de nutrição. 132f. Dissertação (Mestrado em Estudos da Tradução) - Universidade de Brasília, Instituto de Letras, Brasília, 2017.

COSTA, Messias Ramos. Proposta de modelo de enciclopédia visual bilíngue juvenil: Enciclolibras. 151f. Dissertação (Mestrado em Linguística) - Universidade de Brasília, Instituto de Letras, Brasília, 2012.

DOUETTES, Brenno Barros. A tradução na criação de sinais-termos religiosos em libras e uma proposta para organização de glossário terminológico semibilíngue. 2015. 440f. Dissertação (Mestrado em Estudos da Tradução) - Universidade Federal de Santa Catarina, Pósgraduação em Estudos da Tradução, Florianópolis, 2015.

ELAN (version 5.2) [Computer software]. Nijmegen: Max Planck Institute for Psycholinguistics. Disponível em: https://tla.mpi.nl/tools/tla-tools/elan/. Acesso em: 04 jan. 2020. 
INEP, 2019. Avaliações, exames e indicadores da educação básica. Disponível em: http://portal.inep.gov.br/web/guest/conheca-o-inep. Acesso em: 03 de dezembro de 2019.

LACERDA, Cristina Broglia Feitosa de; SANTOS, Lara Ferreira dos e CAETANO, Juliana Fonseca. Estratégias metodológicas para o ensino de alunos surdos. In: Língua Brasileira de Sinais: Libras uma introdução. UAB-UFSCar. São Paulo, 2011.

LESSA, Octacílio. Dicionário básico de biologia. Rio de Janeiro: Editora Ciência Moderna Ltda., 2007.

LIMA, Vera Lúcia de Souza e. Língua de Sinais: proposta terminológica para a área de Desenho Arquitetônico. 2014. 278 f. Tese (Doutorado em Linguística) - Faculdade de Letras, Universidade Federal de Minas Gerais. 2014.

MEC, 2019. Teoria de resposta ao item avalia habilidade e minimiza o "chute" de candidatos. Disponível em: http://portal.mec.gov.br. Acesso em: 03 de dezembro de 2019.

NASCIMENTO, Cristiane Batista do. Terminografia em língua de sinais brasileira: Proposta de glossário ilustrado semibilíngue do meio ambiente, em mídia digital. 222f. Tese (Doutorado em Linguística). Universidade de Brasília, Instituto de Letras, Brasília, 2016.

PLANO NACIONAL DA EDUCAÇÃO (2014-2024). Disponível em: http://pne.mec.gov.br/18-planos-subnacionais-de-educacao/543-plano-nacional-de-educacaolei-n-13-005-2014. Acesso em: 02 de dezembro de 2019.

QUADROS, Ronice Muller de; SOUSA, Aline Nunes de; VARGAS, Roberto Dutra. Tradução do vestibular UFSC/2012 para a Libras. Disponível em: http://www.congressotils.com.br/anais/anais/tils2012_metodologias_traducao_quadrossousa.p df. Acesso em: 02 de dezembro de 2019.

QUADROS, Ronice Muller de; KARNOPP. Lodenir Becker. Língua De Sinais Brasileira: estudos linguísticos. Porto Alegre: Artmed. 2004.

QUADROS, Ronice Muller de. A transcrição de textos do Corpus de Libras. Revista Leitura, v.1, n. 57, p.8-34. 2016.

ROCHA, Luiz Renato Martins; LACERDA, Cristina Broglia Feitosa. Vestibulares vídeogravados em Libras: um novo modo de acesso ao ensino superior federal? Revista Educação Especial, v. 29, n. 56, 2016.

SANTOS, Hadassa Rodrigues. Processos de expansão lexical da libras no ambiente acadêmico. 2017. 130f. Dissertação (Mestrado em Linguística e Língua Portuguesa) Pontifícia Universidade Católica de Minas Gerais, Belo Horizonte, 2017.

SARDINHA, Berber Tony. Lingüística de Corpus. São Paulo: Manole. 2004.

STUMPF, Marianne Rossi.; OLIVEIRA, Janine Soares de.; MIRANDA, Ramon Dutra. Glossário Letras Libras. A trajetória dos sinalários no curso: como os sinais passam a existir. Letras Libras: Ontem, hoje e amanhã. Editora UFSC. Florianópolis-SC. 2015. 
STUMPF, Marianne Rossi.; OLIVEIRA, Janine Soares de; MIRANDA, Ramon Dutra. O Glossário Letras Libras como instrumento para Estudos de Unidades Terminológicas em Libras. Estudos da Língua Brasileira de Sinais II. v.2. Ed. Insular. Florianópolis-SC. 2014.

Recebido em: 21 de janeiro de 2019 Aceito em: 13 de abril de 2020 Publicado em Maio de 2020 